

\section{CONE $920801-29$}

ANL/CMT/CP- -75182

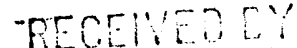 \\ DE93 006404 \\ Title Sheet}

\section{COVER INFORMATION FOR SAE TECHNICAL PAPERS}

In order to ensure that the correct title, author names, and company affiliations appear on the cover and title page of your paper, please provide the information requested below.

\section{PAPER TITLE (upper and lower case):}

Variable Pressure Insulating Jackets for High-Temperature Batteries

\section{AUTHORS (upper and lower case)}

1. P. A. Nelson

2. A. A. Chilenskas

3. R. F. Malecha

4.

5.

6.

7.

8.

9.

10. United States Government or any agency thereof.

\section{COMPANY (upper and lower case)}

1. Argonne National Laboratory

2. Chemical Technology Division

3. 9700 S. Cass Avenue

4. Argonne, IL 60439

\section{DISCLAIMER}

This report was prepared as an account of work sponsored by an agency of the United States Government. Neither the United States Government nor any agency thereof, nor any of their employees, makes any warranty, express or implied, or assumes any legal liability or responsibility for the accuracy, completeness, or usefulness of any information, apparatus, product, or process disclosed, or represents that its use would not infringe privately owned rights. Reference herein to any specific commercial product, process, or service by trade name, trademark, manufacturer, or otherwise does not necessarily constitute or imply its endorsement, recommendation, or favoring by the United States Government or any agency thereof. The views and opinions of authors expressed herein do not necessarily state or reflect those of the

10. 


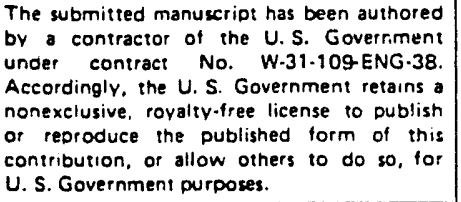

\section{ABSTRACT}

A new method is proposed for controlling the temperature of high-lemperature batteries namely, varying the hydrogen pressure inside of multifoil insulation by varying the temperature of a reversible hydrogen getter. Calculations showed that the rate of heat loss through $1.5 \mathrm{~cm}$ of multifoil insulation between a hol-side temperature of $425^{\circ} \mathrm{C}$ and a cold-side temperature of $25^{\circ} \mathrm{C}$ could be varied between 17.6 $\mathrm{W} / \mathrm{m}^{2}$ and $7,000 \mathrm{~W} / \mathrm{m}^{2}$. This change in heat transfer rate can be achieved by varying the hydrogen pressure between 1.0 Pa and $1000 \mathrm{~Pa}$, which can be done with an available hydrogen gettering alloy operating in the range of $50^{\circ} \mathrm{C}$ to $250^{\circ} \mathrm{C}$. This approach to battery cooling requires cylindrical insulating jackets, which are best suited for bipolar batteries having round cells approximately 10 to $18 \mathrm{~cm}$ in diameter.

\section{INTRODUCTION}

High-temperature batteries under development for electric vehicles, such as lithium/sulfide $\left(425^{\circ} \mathrm{C}\right)$, sodium/sulfur $\left(325^{\circ} \mathrm{C}\right)$, and sodium/nickel chloride $\left(300^{\circ} \mathrm{C}\right)$, require high-efficiency insulating jackets to maintain the temperature witiin an acceptable range. The temperature must be maintained within $25^{\circ} \mathrm{C}$ to $50^{\circ} \mathrm{C}$ (depending on the battery type) of the designated operating temperature and requires controlled cooling to prevent overheating of the batteries. Overheating tends to be most severe during prolonged vigorous discharges for most batteries and during charging for batteries that have high entropic cooling during discharge, such as lithium/disulfide batteries. To limit the thickness of the insulation and, thus, the battery volume, the battery insulation is usually maintained at a vacuum of $1.0 \mathrm{~Pa}\left(7.5 \times 10^{-3}\right.$ torr $)$ or less. This makes possible the use of jackets that are only 1.5 to $3 \mathrm{~cm}$ thick and have heat loss rates of less than $200 \mathrm{~W}$ for a 40-kWh battery.

Much effort has been spent on developing vacuum insulation for high-temperature batteries involving the use of ceramic powders, rigid porous ceramic boards, and multifoil insulation. The factors that must be controlled for an efficient insulation are heat transfer by radiation, conduction through the solid structure, and conduction through residual gases. The lowest rates of conduction through the insulation have been achieved with the use of loosely wrapped multifoil insulation, which consists of thin aluminum foils separated by glass paper. For this type of insulation, the casing walls must support the atmospheric pressure. Thus, only cylindrical shapes appear to be practical. Ceramic structures that are strong enough to support the casing walls against atmospheric pressure transfer more heat than is desired by direct conduction through the ceramic material and by radiation and reflection through the pores.

In a contract funded by the Department of Energy, Union Carbide [1] attempted to make a satisfactory load-bearing insulation by compressing multifoil structures at elevated temperatures, which caused partial sintering of the glass paper used to separate the aluminum foils. The resulting material was sufficiently strong, but its conductivity was too high. Whereas unsintered compressed multifoil structure had about twice the conductivity of loosely packed multifoil of the same thickness, sintered structures had conductivities that were 8 to 10 times higher. The higher conductivity of the compressed structure resulted from increased conduction through the glass fibers because of their greater density and increased contact area, which were even further enhanced by sintering. The moderately low conductivity for unsintered compressed multifoil layers was utilized in a different design approach taken by Argonne National Laboratory in later work in a subcontract to Meyers Tool Co. In that project, an insulating jacket was made by tightly wrapping layers of aluminum foil and glass paper around the inner stainless steel casing of the insulating jacket and then welding the outer casing in place over the insulation [2]. This type of vacuum insulation has the advantages of (1) moderately low conductivity, (2) being adaptable to large flat suriaces in that it supports the stainless steel 
inner and outer casings against atmospheric pressure, and (3) conforming to curved surfaces not easily fitted with flat board-like insulations. However, the compressed multifoil insulation also has disadvantages. It is difficult to degas because of the large area of tightly packed sheet material, and it is moderately dense 10.57 $\mathrm{g} / \mathrm{cm}_{3}$ ), which results in a heavy jacket.

The two approaches to the use of multifoil insulation are shown in Figure 1. In the first approach, four bipolar stack assemblies are encased in a single insulating jacket provided with tightly wrapped insulation that supports the stainless steel inner and outer jacket walls when the insulation is evacuated. In the second approach, each assembly is encased in a single insulating jacket having inner and outer cylindrical stainless steel casings that will withstand atmospheric pressure when the insulation is evacuated.

\section{COOLING METHODS}

Batteries that operate near ambient temperature are usually cooled by direct air cooling of the cell or module casings. This method of cooling is unsafe for hightemperature batteries that contain flammable material because an automatic cooling system would provide air directly to a fire within the jacket. A better approach is to surround the cells and modules with an inert gas, such as nitrogen, and to provide air cooling within heat transfer surfaces such as tubes or plates. This latter method of cooling is the basic approach against which the new proposed method of direct cooling through the insulating jacket wall is compared.

A recent design and calculational study at ANL has shown that variation in the jacket pressure over the range 1 to $1000 \mathrm{~Pa}\left(10^{-2}\right.$ to 10 torr) will provide the necessary control over the rate of heat loss from the jacket. At the low-pressure end of the range, the mean free path of the gas molecules greatly exceeds the size of the interstices in the insulation, thus resulting in low conductivity through the gas. The variation in pressure can be achieved by the admission of air to raise the heat loss rate, and the use of a small mechanical vacuum pump to lower the cooling rate. Another method of varying the pressure is by changing the temperature of a getter which reversibly absorbs and desorbs hydrogen in the gas space. A getter, typically $\mathrm{Zr}-24.6 \% \mathrm{~V}-5.4 \% \mathrm{Fe}$ (St 707 alloy supplied by SAES Getters/U.S.A., Inc.), is normally used to remove gases in vacuum jackets and is effective for nitrogen, oxygen, and hydrogen, the main gaseous constituents in a vacuum jacket. Alloys of the same metals, but at different concentrations, or other similar alloys will irreversibly getter nitrogen and oxygen but permit variation in the hydrogen pressure over the desired range by varying the getter temperature. As an example, getter alloy St 737 (SAES Getters/U.S.A., Inc.), which has the composition $\mathrm{Zr}-33 \% \mathrm{~V}-33 \% \mathrm{Fe}$, will store hydrogen at $2500 \mathrm{~Pa}-\mathrm{L} / \mathrm{g}$ (20 torr-L/g) without ailoy embritilement [3]. At this concentiation, the equilibrium pressures are about $1.0 \mathrm{~Pa}$ at $50^{\circ} \mathrm{C}$ and
$1000 \mathrm{~Pa}$ at $250^{\circ} \mathrm{C}[3,4]$. Such a gettering material, with a controlled resistance heater, can be used to vary the hydrogen pressure within the insulation and, thus, the rate of heat loss. Either method of pressure control, the use of a mechanical vacuum pump or the variation in the getter temperature, should be effective in controllin' the rate of battery cooling, and both methods have common advantages and special requirements compared to more conventional means of cooling. The use of air and a mechanical vacuum pump requires valves but the use of hydrogen and a getter does not

Pressure variation for heat loss control requires a loose insulation or at least an insulation with welldistributed gas passages to permit rapid flow of gas to the vacuum pump or getter. To be practical for temperature control, it should be possible to change the pressure within the desired range by at least two ordirs of magnitude within 30 minutes. The most direct approach to meeting this condition is to design the jacket with internal and external metal casings that can withstand a full vacuum without support by the insulation. This approach would limit the application of the pressure variation method of battery cooling to cylindrical jackets of no more than about $20 \mathrm{~cm}$ diameter. In tests at Argonne, jackets with flat sides, for which the metal casings were supported by compressed multifoil insulation, required long periods (several days) for the initial evacuation because of the restricted gas flow passages. The use of pressure variation in the jacket for cooling rate control wourd be inappropriate for such batteries. Specially designed insulation having large distributed passages might circumvent this probleri.

The use of cylindrical insulating jackets, which is favored by the proposed cooling method, is best suited for bipolar batteries having round cells approximately 10 to $18 \mathrm{~cm}$ in diameter. Fortunately, this is a promising design for achieving high specific energy with high-temperature batteries. Lithium/sulfide [5] and sodium/nickel chloride batteries [6], which can be fabricated with long strings of series-connected cells because a short circuit is formed on cell failure, are especially favorable for the bipolar design.

\section{HEAT TRANSFER CALCULATIONS}

Heat transfer calculations were made for loosely stacked multifoil insulation. As an approximation, the effects of the glass paper separating the aluminum foil heat shields on the heat transfer rate were ignored. The glass paper reflects radiated heat but, tending to offset this effect, it also transmits heat by conduction in regions where it touches the foil. With the very thin, low density, lightly compressed paper under consideration, these effects are believed to be minor. With this assumption, the heat transfer rate between heat shields was calculated by the equation:

$$
q=A \sigma\left(\frac{\varepsilon}{2-\varepsilon}\right)\left(T_{1}^{4}-T_{2}^{4}\right)
$$


where $\mathrm{q}=$ heat transfer rate, $\mathrm{W}$

$A=$ area, $m^{2}$

$\sigma=$ Stefen-Boltzmann constant, $5.67 \times 10^{-8} \mathrm{~W} / \mathrm{m}^{2}-\mathrm{K}^{4}$

$\varepsilon=$ emissivity of aluminum foil

$T_{1}=$ temperature of the hotter shield, $\mathrm{K}$

$T_{2}=$ temperature of the cooler shield, $K$

The emissivity of the aluminum foil was taken to be 0.15 throughout the temperature range of interest. With a given value of the hot-side temperature and an assumed value for the heat transfer rate per unit area $(q / A)$, the temperatures of the heat shields were calculated by means of Equation (1). This procedure was repeated in an iterative process with adjusted values of q/A until the temperature on the 40 th heat shield (1-cm thick insulation) was $25^{\circ} \mathrm{C}$, the given coldside temperature. The results of this calculation for hotside temperatures between $200^{\circ} \mathrm{C}$ and $450^{\circ} \mathrm{C}$ are shown in Figure 2. The results for 60 heat shields $(1.5-\mathrm{cm}$ thick insulation having 40 shields $/ \mathrm{cm}$ ) are also shown. In the Union Carbide study discussed above [1], a packing density of 40 shields $/ \mathrm{cm}$, which we used in our calculations, was found to give near the minimum conductance for a given thickness of alternating layers of aluminum foil of $7.6-\mu \mathrm{m}(0.3$ mils $)$ thickness and Grade 233 Dexter paper of $80-\mu \mathrm{m}$ (3.2 mils) thickness. Measurements in that study provided heat transter rates on similar materials that were $28 \%$ lower than those shown in Figure 2. The higher calculated values may have resulted from the assumption that the effect of the glass paper on the heat transfer rate was negligible. Also, a lower value for the emissivity 0.11 , instead of the value actually used 0.15 , would bring the calculated values very close to the measured value. For the purpose of this study, the calculated values were considered sufficiently accurate without adjustment.

The effects of adding air or hydrogen to the insulation were also considered. To account for the gas conductivity, an additional term was added to Equation (1):

$\mathrm{q}=A \sigma\left[\frac{\varepsilon}{2-\varepsilon}\right]\left(\mathrm{T}_{1}^{4}-\mathrm{T}_{2}^{4}\right)+A\left(\frac{\mathrm{k}}{\mathrm{d}}\right)\left(\mathrm{T}_{1}-\mathrm{T}_{2}\right)$

where $\mathrm{k}=$ gas conductivity, $\mathrm{W} / \mathrm{m}-\mathrm{K}$

$d=$ distance between aluminum heat shields, $m$

Values of the thermal conductivity of air and hydrogen over the temperature range of $27^{\circ} \mathrm{C}$ to $527^{\circ} \mathrm{C}(300$ to $800 \mathrm{~K})$ from Ref. [7] were curve fitted. The curves are shown in Figure 3 and were used in solving Equation (2).

In calculations carried out in a manner similar to those used for evacuated insulation, the temperature distribution within the insulation was calculated for airfilled and hydrogen-filled insulation. With a given value of the hot-side temperature ot $425^{\circ} \mathrm{C}$ and an assumed value for the heat transter rate per unit area $\left(q^{\prime} A\right)$, the temperatures of the heat shields were calculated by means of Equation (2), with the thermal conductivities adjusted for the temperatures of the individual heat shields. This procedure was repeated in an iterative process with adjusted values of q/A until the temperature on the 60 th heat shield was $25^{\circ} \mathrm{C}$, the given cold-side temperature. The results for the temperature distribution within the insulation are presented in Figure 4 for vacuum, hydrogen, and air atmospheres within the insulation. The calculated heat transfer rates are given in the right-hand column of Table 1 along with similar calculations for a hot-side temperature of $300^{\circ} \mathrm{C}$ and $1.0 \mathrm{~cm}$ insulation thickness. Table 1 also provides data on the heat transfer rate through compressed insulation under vacuum. This result was derived from a measurement made in the Union Carbide study [1].

A comparison of the calculated values in Table 1 indicates a large increase in the heat transier rate on the admission of gas to the insulation and shows that hydrogen is more effective than air. For loosely stacked insulation, the gas pressure should be at least $1000 \mathrm{~Pa}$ (10 mbar) for the full conductivity of the gas to take effect. Below that level, the conductivity of the gas is reduced by the effect of the long mean free path of the molecules relative to the size of the interstices within the insulation. Below $1 \mathrm{~Pa}$, the heat transfer rate is independent of pressure, being essentially that for a full vacuum. In the intermediate pressure region (1 to $1000 \mathrm{~Pa}$ ), the curve of heat transfer rate versus pressure is "S" shaped, connecting the lower plateau below $1 \mathrm{~Pa}$ to the upper plateau above $1000 \mathrm{~Pa}$ and having a pressure range in which the heat transfer rate is approximately proportional to pressure. The heat transfer rate in this region is difficult to calculate, and only these semi-quantitative estimates are available.

\section{BATTERY JACKET DESIGN}

Our calculations have shown that $10-\mathrm{kWh}$ bipolar battery assemblies for either lithium/sulfide [5] or sodium/nickel chloride [6] could be designed with dimensions, not including thermal insulation, of approximately $15 \mathrm{~cm}$ in diameter and $120 \mathrm{~cm}$ long. A $40-k W h$ battery for an electric vehicle would require four such assemblies and could be designed to deliver about $90 \mathrm{~kW}$ of power. The two design approaches shown in Figure 1 were evaluated in a calculational design study. As shown in Table 2, there is a considerable difference in the density of the insulation for these two design approaches. Mainly because of this factor, the insulating jacket for a $40-\mathrm{kWh}$ battery would be only $62 \%$ as heavy for the second approach (28.2 $\mathrm{kg}$ versus $45.8 \mathrm{~kg}$ ), which has loosely wrapped insulation. The heat loss rate through the insulation would be essentially the same for both approaches, 44 $W$ for the tightly wrapped insulation and $48 W(12 W \times 4$ modules) for the loosely wrapped insulation

The heat loss rates through the power leads become an important factor for the improved insulation 
designs discussed above. Calculations were made for heat losses through copper leads of $30 \mathrm{~cm}$ length, assuming no heat loss from the leads to the insulation. Heat generation within the leads and variation of the thermal and electrical conductivities with temperature were taken into account. By iterative calculations, the diameters of the leads were sized to provide a moderate heat loss rate at the maximum current. Leads having somewhat smaller diameters would overheat because of ohmic heating. The heat losses shown in Table 2 are at standby or at low power. For both design approaches, there are two parallel strings, each providing a maximum of $180 \mathrm{~A}$. For the design having all assemblies in one thermal jacket, the assembly leads are connected to single leads to positive and negative battery terminals. These leads deliver up to $360 \mathrm{~A}$ and lose a total of $41 \mathrm{~W}$ of heat by conduction to external leads at $100^{\circ} \mathrm{C}$. The loosely wrapped insulation approach requires four jackets, each having two leads (positive and negative), which deliver up to $180 \mathrm{~A}$ and lose a total of $20.5 \mathrm{~W}$ of heat. Thus, the four sets of leads for the entire $40-\mathrm{kWh}$ battery lose $82 \mathrm{~W}$, twice as much as the leads from the $40-\mathrm{kWh}$ battery in a single thermal jacket. The total heat loss from these four sets of leads could be reduced ff. $32 \mathrm{~W}$ to about 50 or $60 \mathrm{~W}$ by minimizing the lengths of the leads connecting the modules in series and providing ample thermal insulation on these external leads. In Table 2 no allowance was made for this savings in heat loss for the four-module battery.

The total heat loss rates from both batteries are acceptably low. These low rates result from the very compact design of the bipolar batteries and the resulting small surface area of the thermal jacket per unit of energy stored by the battery.

Table 2 also provides data on the cooling rate through the insulation. The battery with tightly wrapped insulation is designed to be cooled by air flowing through tubes between the stack assemblies to provide a cooling rate of $6,000 \mathrm{~W}$. For the cylindrical module with loosely wrapped insulation, a design cooling rate of $2500 \mathrm{~W} / \mathrm{m}^{2}$ was used. This rate of heat transfer for 1.5 $\mathrm{cm}$ insulation is considerably lower than the 7,000 $\mathrm{W} / \mathrm{m}^{2}$ value for hydrogen-filled insulation shown in Figure 4 and Table 1 . The more conservative value was used because it is clearly adequate and it can be achieved with less addition of hydrogen, perhaps to a pressure of only 100 to $500 \mathrm{~Pa}$. The design goal used here of $2,500 \mathrm{~W} / \mathrm{m}^{2}$ could not be achieved with air. Hydrogen is clearly more efficient than air for assisting in battery cooling. Also, hydrogen pressure can be controlled by the getter temperature and does not require the use of valves.

Figure 5 shows a diagram of a cylindrical battery module having loosely wrapped insulation. The amount of insulation needed between the getter and outside jacket casing would depend on the specific gettering alloy selected and the temperature required for the low heat loss mode of operation. An alternative io locating the gettering unit within the jacket is to provide an external gettering unit and to connect this unit to all of the modules with welded tubing. Such an approach would require a getter that operates effectively at room temperature for removing oxygen, nitrogen, and hydrogen. A getter supplied by SAE Getters/U.S.A., Inc., designated $S t 737$, is such a getter. For this application, approximately $5000 \mathrm{~Pa}-\mathrm{L}(0.0045 \mathrm{~g})$ of hydrogen must be released by the getter for each module to provide a hydrogen pressure of $1000 \mathrm{~Pa}$ within the insulation at the average temperature. Each gram of getter alloy will store $2500 \mathrm{~Pa}-\mathrm{L}$ of hydrogen without embrittlement. Thus, 20 to $50 \mathrm{~g}$ of getter for each module would provide sufficient getter alloy for removing oxygen and nitrogen irreversibly and would provide for the storage of the required hydrogen.

\section{DISCUSSION}

Supporting the bipolar assembly in the center of the loosely wrapped insulation of the cylindrical module needs additional design effort. One approach is to wrap the insulation layers in widths of about $30 \mathrm{~cm}$ with overlapping of about 1 to $2 \mathrm{~cm}$ between simultaneously wrapped sections. The overlapped region would have twice the density of material (still less than tightly wrapped insulation) and assist in maintaining the position of the battery assembly without compression of the main body of insulation.

For cylindrical bipolar battery jackets, the pressure variation technique for controlling cooling by means of getters has several attractive features:

1) The gettering system normally provided for maintaining the vacuum in the insulating jacket may be used for enhancing the rate of heat loss with little additional cost.

2) Elimination of the gas blower and piping associated with conventional air cooling of batteries would reduce costs.

3) No cooling gas tubing enters the hightemperature region and, thus, a path for heat loss is avoided.

4) Loosely wrapped layers of aluminum foil and glass-fiber paper weigh less and cost less than currently used insulating systems that support the inner and outer jacket casings.

5) For a cylindrical bipolar module, heat is uniformly removed from the cylindrical surface of the bipolar stack, which would limit temperature differentials and extend cell life.

6) The separation of the battery into several separate modules may improve the use of space in the vehicle and makes possible more even distribution of the battery weight.

7) Individual modules that fail can be replaced more easily and at less cost than replacing part of a battery within a single insulating jacket.

\section{ACKNOWLEDGMENT}

The authors wish to thank J. E. Harmon for editing the text. The work was funded by the U.S. Department 
of Energy, Conservation and Renewable Energy, under Contract No. W-31-109-ENG-38.

\section{REFERENCES}

[1] Union Carbide, Linde Division, "Insulation Development for High-Temperature Batteries for Electric Vehicle Application," Final Report, Contract No. EM-78-C-01-5160, December 1979.

[2] A. A. Chilenskas, R. F. Malecha, A. F. Tummillo, F. J. Meyer, and J. R. Missig, "Development o; Compressed Multifoil Insulation for HighTemperature Batteries and Other Applications," Argonne National Laboratory Report ANL-89-4 (1989).

[3] G. Bonizzoni, A. Conte, G. Gatto, G. Gervosini, F. Ghezzi, and M. Rigamonti, "Tritium Storage Plant Based on a Combination of St 707 and St 737 Getter Alloy Beds for High Field Fusion Machines," presented at the 11 th International Vacuum Congress, Cologne, Germany, September 25-29, 1989.

[4] F. Doni, C. Boffito, and B. Ferrario, "Hydrogen Isotope Sorption and Recovery by a Nonevaporable Getter Combined with a Chemical Compressor Material," J. Vac. Sci. Technol. A 4(6), November/December 1989, p. 2447 (1986).

[5] P. A. Nelson and T. D. Kaun, "Modeling of Lithium/Sulfide Batteries for Electric Vehicles and Hybrid Vehicles," Proc. of 26th Intersoc. Energy Conversion Eng. Conf., Boston, MA, August 4-9, 1991, Vol. 3, p. 417 (1991).

[6] P. A. Nelson and J. Prakash, "Modeling of Sodium/Nickel Chloride Batteries for Electric Vehicles, Proc. of the Electrochem. Soc. Mtg., Phoenix, AZ, October 13-18, 1991, Vol. 91-10, p. 122 (1991).

[7] Y. D. Touloukian, P. E. Liley, and S. C. Saxena, "Thermal Conductivities of Nonmetallic Liquids and Gases," IFI/Plenum, New York, 1970.

Table 1. Heat Transfer Rates through Load-Bearing and Loosely Stacked Multifoil Insulation

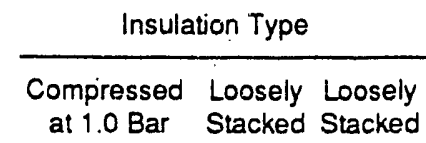

\begin{tabular}{lccc}
\hline Heat Shields per Centimeter & 159 & 40 & 40 \\
Hot-Side Temperature, ${ }^{\circ} \mathrm{C}$ & 449 & 300 & 425 \\
Cold-Side Temperature, ${ }^{\circ} \mathrm{C}$ & 25 & 25 & 25 \\
Insulation Thickness, $\mathrm{Cm}$ & 2.0 & 1.0 & 1.5 \\
Heat Transfer Rates, & & & \\
$\quad$ Measured at Vacuum $(0.1 \mathrm{~Pa})$ & 23.9 & -- & \\
$\quad$ Calculated & & & \\
$\quad$ Vacuum (0.1 Pa) & - & 11.5 & 17.6 \\
$\quad$ Air Pressure (>1000 Pa) & - & 1000 & 1070 \\
$\quad$ Hydrogen Pressure (>1000 Pa) & - & 6600 & 7000 \\
\hline
\end{tabular}

Aluminum foil thickness, $7.6 \mu \mathrm{m}(0.3 \mathrm{mils}$ ); glass paper (Dexter 233) thickness, $81 \mu \mathrm{m}$ (3.2 mils).
Table 2. Comparison of Two Types of Insulating Jackets for High-Temperature Bipolar Batteries

$425^{\circ} \mathrm{C}$ Operating Temperature

\begin{tabular}{|c|c|c|}
\hline & $\begin{array}{c}\text { Tightly } \\
\text { Wrapped } \\
\text { Insulation }\end{array}$ & $\begin{array}{l}\text { Loosely } \\
\text { Wrapped } \\
\text { Insulation }\end{array}$ \\
\hline Energy stored per module, $\mathrm{kWh}$ : & 40 & 10 \\
\hline Number of stacks per assembly: & 4 & 4 \\
\hline Number of assemblies per module: & 4 & 1 \\
\hline \multicolumn{3}{|l|}{ Bipolar stack assembly dimensions } \\
\hline Diameter, cm: & 15 & 15 \\
\hline Length, $\mathrm{cm}$ : & 120 & 120 \\
\hline \multicolumn{3}{|l|}{ Jacket dimensions } \\
\hline Height or diameter, $\mathrm{cm}$ : & 19.5 & 18.5 \\
\hline Width, $\mathrm{cm}$ : & 64.7 & 18.5 \\
\hline Length, $\mathrm{cm}$ : & 127.2 & 125.7 \\
\hline \multicolumn{3}{|l|}{ Jacket volume for $40-k W h$ battery } \\
\hline Actual, L: & 150 & 134 \\
\hline Based on rectangular dimensions, $L$ : & 160 & 171 \\
\hline Insulation density, $\mathrm{g} / \mathrm{cm} 3$ : & 0.57 & 0.143 \\
\hline \multicolumn{3}{|l|}{ Insulation thickness } \\
\hline Side walls, cm: & 2.0 & 1.5 \\
\hline End walls, $\mathrm{cm}$ : & 3.0 & 2.25 \\
\hline Stainless steel casing thickness, $\mathrm{cm}$ : & 0.038 & 0.038 \\
\hline \multicolumn{3}{|l|}{ Weight breakdown for module } \\
\hline Stainless steol casings, kg: & 11.8 & 4.0 \\
\hline Insulation, $\mathrm{kg}$ : & 24.0 & 1.5 \\
\hline Heating system, kg: & 6.0 & 1.0 \\
\hline Cooling system, kg: & 4.0 & 0.5 \\
\hline Total, kg: & 45.8 & 7.1 \\
\hline Jacket weight for $40-\mathrm{kWh}$ battery, $\mathrm{kg}$ : & 45.8 & 28.2 \\
\hline \multicolumn{3}{|l|}{$\begin{array}{l}\text { Heat loss rates for module } \\
\text { Insulation }\end{array}$} \\
\hline Per unit area, $W / \mathrm{m}^{2}$ : & 22.6 & 17.6 \\
\hline Total, W: & 44 & 12 \\
\hline \multicolumn{3}{|l|}{ Feedthroughs } \\
\hline Maximum current, A: & 360 & 180 \\
\hline Power-lead diameter, cm: & 0.80 & 0.56 \\
\hline Power-lead losses, W: & 41 & 20.5 \\
\hline Auxiliary lead losses, W: & 4 & 2 \\
\hline Gas cooling lines, W: & 5 & 0 \\
\hline Total heat losses, W: & 94 & 34 \\
\hline Heat loss rates for $40-k W h$ battery, $W$ : & 94 & 138 \\
\hline \multicolumn{3}{|l|}{$\begin{array}{l}\text { Maximum cooling rates for module } \\
\text { Insulation }\end{array}$} \\
\hline Per unit area, W/m²: & 22.6 & $2,500^{\circ}$ \\
\hline Total, $\mathbf{W}:$ & 44 & $1,700^{\circ}$ \\
\hline Cooling by air through tubes, $W$ : & 6,000 & 0 \\
\hline Balance of system, $W$ : & 50 & 22.5 \\
\hline Total cooling rates, W: & 6,100 & 1,700 \\
\hline Maximum cooling rates for $40-\mathrm{kWh}$ battery, $\mathrm{W}$ : & 6,100 & 6,800 \\
\hline
\end{tabular}

"Hydrogen filled. 


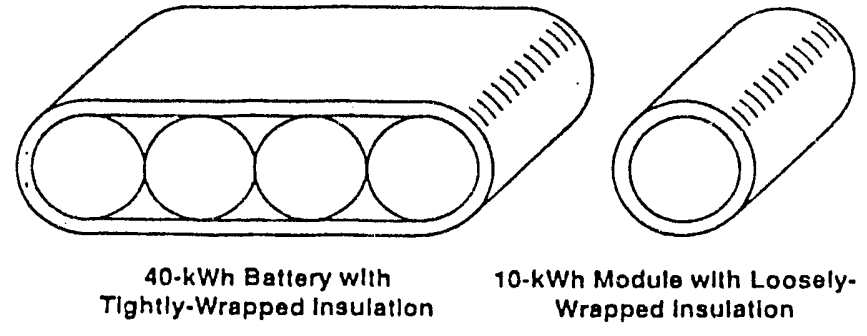

Fig. 1. High-temperature bipolar battery cross sections showing multifoil vacuum insulation. The tightly wrapped insulation supports the inner and outer stainless steel casings, but the cylindrical module has loosely wrapped insulation and self-supporting casings.

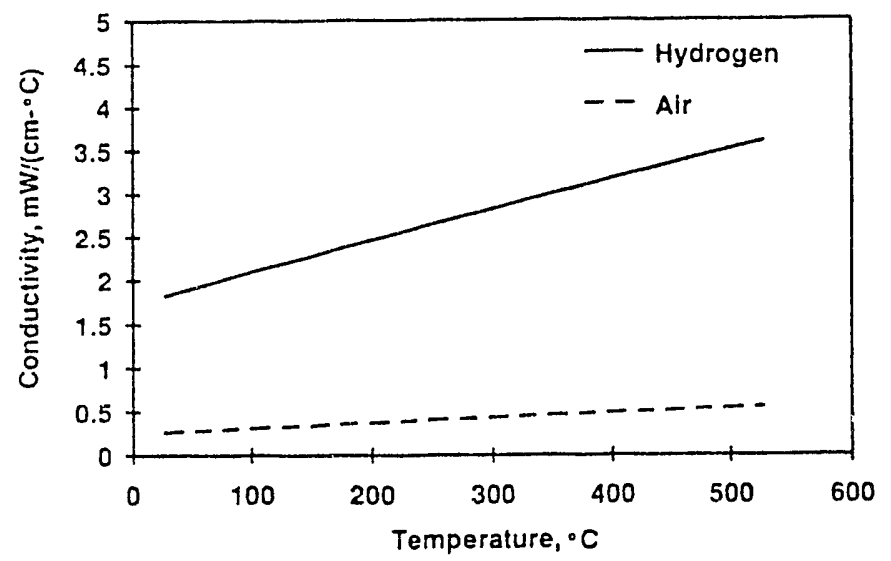

Fig. 3. Thermal conductivities of air and hydrogen as a function of temperature. Curves fitted to preferred values of Ref. [7].

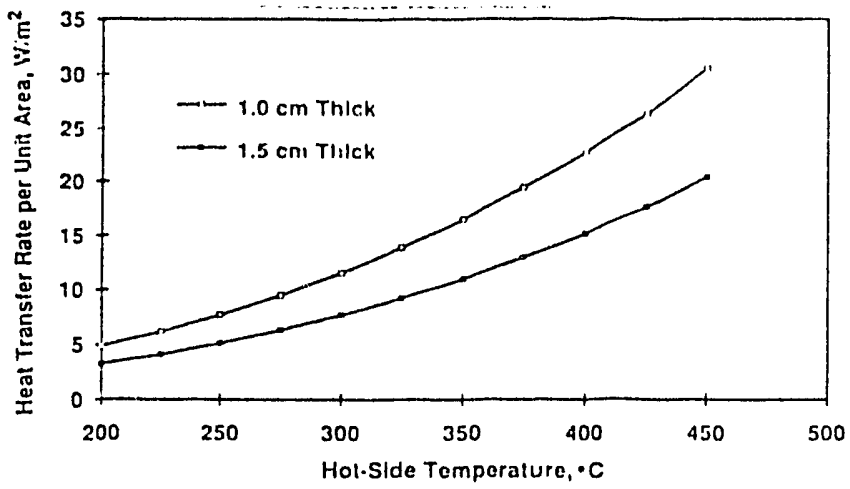

Fig. 2. Calculated heat-transfer rates through evacuated multifoil insulation having 40 shields per centimeter of thickness and a cold-side temperature of $25^{\circ} \mathrm{C}$.

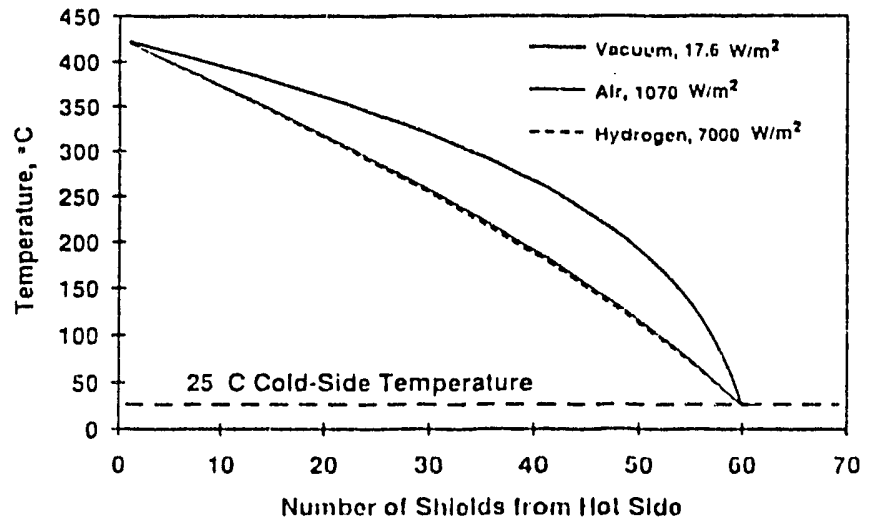

Fig. 4. Temperature distribution within multifoil heat shields for a hot-side temperature of $425^{\circ} \mathrm{C}$ with evacuated insulations and insulations containing hydrogen and air. The heat-transfer rates were selected to result in a cold-side temperature of $25^{\circ} \mathrm{C}$ on the 60 th heat shield for $1.5-\mathrm{cm}$ thick insulation containing 40 heat shields per centimeter.

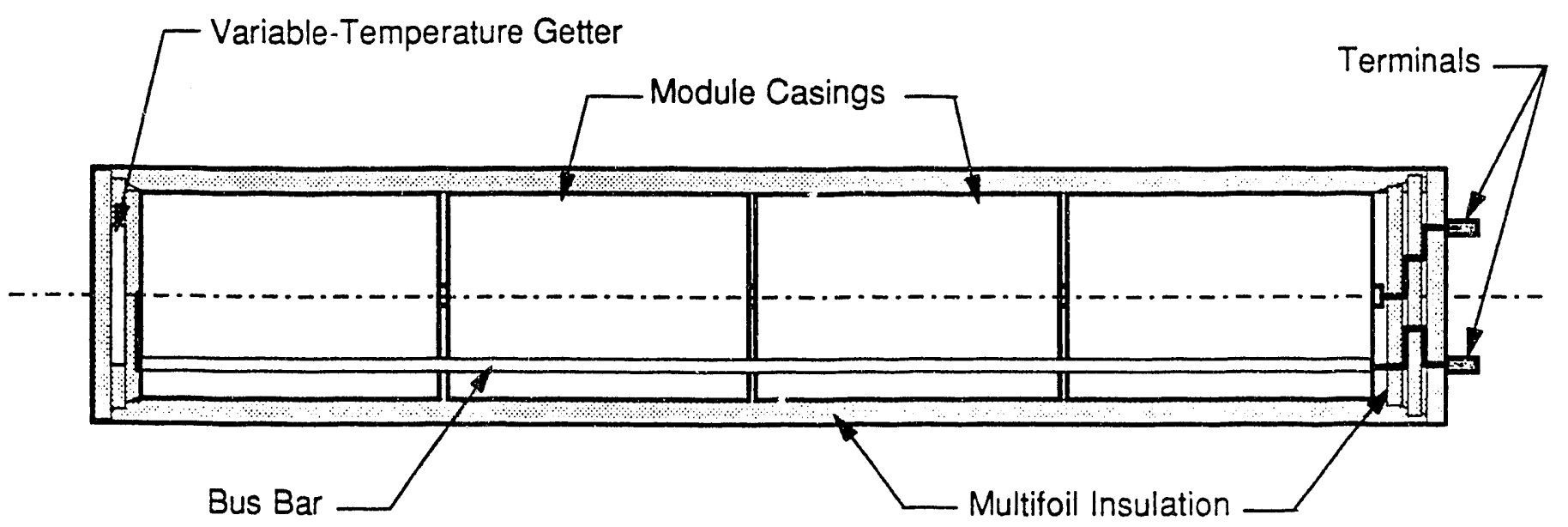

Fig. 5. A diagram of a 10-kWh bipolar battery module with loosely wrapped multifoil insulation. The temperature of the getter alloy can be controlled to release or sorb hydrogen and thus control the rate of heat loss between $34 \mathrm{~W}$ and $1700 \mathrm{~W}$. 

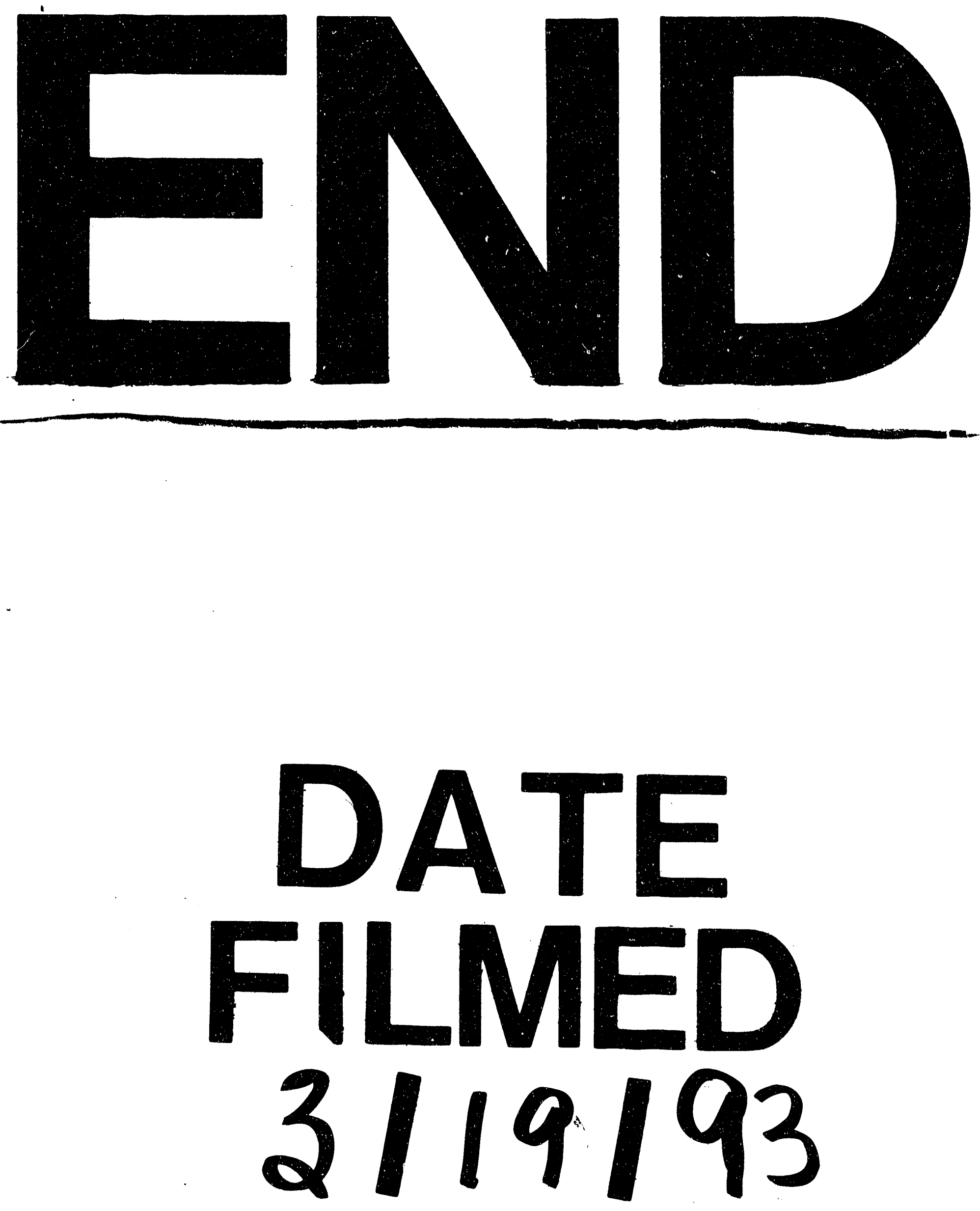
